\title{
Comparación Histológica e Inmunohistoquimica de Muestras de Tejido Procesadas por la Técnica Convencional o por el Método Simplificado de Acetonas
}

\author{
Histological and Immunohistochemical Comparison of Tissue Samples \\ Processed by the Conventional Technique or the Acetone Simplified Method
}

"Pablo Martínez Rivera; *Ana Karina Piña Osuna; **Adolfo Soto Domínguez \& ***ubén García Garza

MARTÍNEZ, R. P.; PIÑA, O.A. K.; SOTO, D. A. \& GARCÍA, G. R. Comparación histológica e inmunohistoquimica de muestras de tejido procesadas por la técnica convencional o por el método simplificado de acetonas. Int. J. Morphol., 29(2):575-580, 2011.

RESUMEN: La técnica convencional (TC) que usa alcohol como agente deshidratante, es un método útil en los laboratorios de Histología y Anatomía Patológica. Recientemente, un nuevo método simplificado con acetona (TA) fué diseñado en un intento por reducir el tiempo de procesamiento de los tejidos (de 12 a 4 horas), el costo de reactivos, y como un factor importante para tener un diagnóstico veraz y rápido. En este trabajo se compararon los parámetros histológicos e inmunohistoquímicos en muestras de cáncer de mama, colon y riñón tratadas con ambos métodos. Los cortes fueron teñidos con H \& E o tricrómico de Masson. También se llevó a cabo inmunohistoquímica con anticuerpos especificos para la identificación de citoqueratinas AE1/AE3, el receptor de estrógeno y receptor de progesterona. Se realizó un estudio ciego por tres especialistas en morfológía, quienes evaluaron la tinción nuclear, tinción del citoplasma y friabilidad o cambios en la estructura tisular. La especificidad y sensibilidad de la unión de los anticuerpos también fueron evaluadas. Los valores obtenidos para cada parámetro se analizaron estadísticamente con la prueba t de Student. Nuestros resultados muestran que los métodos de TC y TA no modificaron características histológicas como el patrón de tinción, ni se detectaron cambios tisulares. La positividad de la inmunohistoquímica fué similar para ambos métodos. No se observó diferencia estadística entre TC y TA. Nuestros resultados sugieren que la aplicación de la TA no modificó las propiedades histológicas e inmunohistoquímicas y que podría ser un método útil en el análisis morfológico.

PALABRAS CLAVE: Alcohol; Acetona; Procesamiento histológico; Inmunohistoquímica.

\section{INTRODUCCIÓN}

La técnica histológica convencional (TC) es el método más utilizado para el procesamiento de tejidos, la cual consiste en la transformación de una muestra en delgados cortes teñidos capaces de ser observados al microscopio, puede ser realizada ya sea manual o automatizada con una duración de aproximadamente 12 horas (Prophet, 1995). Dentro de los pasos, la deshidratación es la que ocupa la mayor parte del tiempo requerido con un promedio de 8 horas, utilizando concentraciones graduales de alcohol etílico (Montuenga et al., 2009). La acetona es un agente deshidratante incoloro, flamable, miscible en agua y en otros solventes orgánicos, la cual tiene una mayor capacidad de extraer el agua de los tejidos comparada con la mostrada por el alcohol (Bancroft \& Gamble, 1997). El llamado Mé- todo Histotecnológico de Procesamiento Simplificado o Técnica de Acetonas (TA) se desarrolló por la necesidad de obtener cortes histológicos en menor tiempo; Romero (1993) estableció las concentraciones y diluciones de acetona óptimas en la aplicación de éste método para el procesamiento de biopsias de tejido nervioso, obteniendo resultados satisfactorios y además de una reducción significativa de 12 a 3:20 horas en el tiempo del procesamiento de las muestras en comparación con el método convencional con alcohol.

El objetivo de este trabajo fue comparar parámetros histológicos e inmunohistoquímicos en muestras de tejido procesadas por el método convencional de deshidratación con alcoholes y con la TA.

\footnotetext{
* Departamento de anatomía patológica. Hospital de especialidades No25. Monterrey, Nuevo León, México.

** Departamento de Histología. Facultad de Medicina, Universidad Autónoma de Nuevo León, Monterrey, Nuevo León, México.
} 


\section{MATERIAL Y MÉTODO}

En este estudio se incluyeron 90 muestras de biopsias excisionales de los siguientes órganos: glándula mamaria, colon y riñón. Éstas muestras fueron inicialmente fijadas con formalina al $10 \%$, posteriormente se obtuvieron dos porciones de tejido de cada muestra, una se procesó por la TC la otra por la TA. Finalmente estas muestras se incluyeron en bloques de parafina. En la Tabla I se detalla el procedimiento utilizado en ambas técnicas.

De las muestras incluidas en bloques de parafina se obtuvieron cortes histológicos de 5 micras de espesor, y teñidos simultáneamente con Hematoxilina y Eosina (H y E) para su evaluación inicial. Posteriormente de éstos cortes se seleccionaron áreas de interés comparativas para ambas técnicas y se disecaron de los bloques de parafina utilizando la técnica de elaboración de Histoarreglos modificada por Hidalgo et al. (2003). De estos bloques se obtuvieron cortes de 4 micras los cuales fueron teñidos por la técnica de Tricrómico de Masson e inmunohistoquímica utilizando el sistema de detección EnVision y anticuerpos específicos para la identificación de: receptores de estrógenos y progesterona, en las muestras de glándula mamaria y cocktail de citoqueratinas AE1/AE3 en las de riñón y colon. Éstos reactivos se obtuvieron de la casa comercial Dako.

Para la evaluación de los resultados se diseñó un estudio ciego en donde participaron tres especialistas en morfología. En cuanto a las muestras teñidas con $\mathrm{H}$ y E se con- sideraron tres parámetros: 1.-calidad de la tinción nuclear, 2.-calidad de la tinción del citoplasma, y 3.- calidad general del corte histológico considerando rasgos específicos como la presencia de fisuras, fragilidad tisular y homogeneidad de la tinción. Para éstos parámetros se asignaron valores en una escala del 1-10, en donde 1-2 corresponden a muestras de muy mala calidad, 3-4 mala calidad, 5-6 calidad regular, 7-8 buena calidad, 9-10 excelente calidad. Para la técnica de Tricrómico de Masson se consideraron los parámetros 1 y 2 ya descritos, además se evaluó como número 4.- la tinción de las fibras colágeno. De éstos valores se obtuvieron valor promedio y desviación estándar y se analizaron estadísticamente con la prueba de T-student para un valor de significancia $p \leq 0,5$. En la técnica de inmunohistoquímica se comparó la especificidad y sensibilidad de los anticuerpos empleados en las muestras procesadas por cada una de las técnicas.

\section{RESULTADOS}

Tinción con Hematoxilina y Eosina y Tricrómico de Masson

Para los parámetros 1 y 2 , los valores promedio obtenidos del análisis de las muestras procesadas por la TA se encontraron dentro del rango de 7,2 $\pm 0,5-8,1 \pm 0,9$ (buena calidad), siendo éste valor similar al obtenido por las de la TC que estuvieron entre $7 \pm 1,3-7,6 \pm 1,3$. No se observó diferencia estadística significativa (Tabla II).

Tabla I. Protocolo de procesamiento de tejidos tanto por la TC como por la TA.

\begin{tabular}{lclc}
\hline \multicolumn{1}{c}{ Técnica histológica convencional } & \multicolumn{1}{c}{ Técnica de acetonas } & \\
\hline Pasos y soluciones & $\begin{array}{c}\text { Tiempo } \\
\text { (minutos) }\end{array}$ & Pasos y soluciones & $\begin{array}{c}\text { Tiempo } \\
\text { (minutos) }\end{array}$ \\
\hline 1. Alcohol etílico 60\% & 60 & $\begin{array}{l}\text { 1. Lavado en agua } \\
\text { corriente }\end{array}$ & 5 a 10 \\
2. Alcohol etílico70\% & 60 & 2. Acetona 90\% & 20 \\
3. Alcohol etílico 80\% & 60 & 3. Acetona 100\% & 20 \\
4. Alcohol etílico 96\% & 60 & 4. Acetona 100\% & 20 \\
5. Alcohol etílico 96\% & 60 & 5. Acetona Xilol 1:1 & 20 \\
6. Alcohol etílico Absoluto & 60 & 6. Xilol & 20 \\
7. Alcohol etílico Absoluto & 60 & 7. Parafina & 45 \\
8. Etanol Abs y Xilol 1:1 & 60 & 8. Parafina & 45 \\
9. Xilol & 60 & & \\
10. Xilol & 60 & & $3: 20$ \\
11. Parafina líquida & 60 & & \\
12. Parafina líquida & 60 & & \\
Tiempo total (Horas) & $12: 00$ & & \\
\hline
\end{tabular}


MARTíNEZ, R. P.; PIÑA, O. A. K.; SOTO, D. A. \& GARCÍA, G. R. Comparación histológica e inmunohistoquimica de muestras de tejido procesadas por la técnica convencional o por el método simplificado de acetonas. Int. J. Morphol., 29(2):575-580, 2011.

Tabla II. Valores obtenidos en la evaluación histológica para las muestras teñidas con HyE. 1y 2 corresponden a muestras de muy mala calidad, 3-4 mala calidad, 5-6 regular, 7-8 buena, 9-10 excelente.

\begin{tabular}{lccc}
\hline Tipo de muestra & Promedio de tinción nuclear & Promedio de tinción del citoplasma & Técnica empleada \\
\hline Glándula mamaria & $7.6 \pm 1$ & $7.4 \pm 1$ & TC \\
Colon & $7.1 \pm 1.3$ & $7 \pm 1.3$ & TC \\
Riñón & $7.3 \pm 1.2$ & $7.6 \pm 1.3$ & TC \\
Glándula mamaria & $8.1 \pm 0.9$ & $7.5 \pm 1$ & TA \\
Colon & $7.2 \pm 0.5$ & $7.2 \pm 0.5$ & TA \\
Riñón & $7.4 \pm 0.7$ & $7.4 \pm 0.8$ & TA \\
\hline
\end{tabular}

Tabla III. Valores obtenidos en la evaluación de la calidad general del corte histológico. 1y 2 corresponden a muestras de muy mala calidad, 34 mala calidad, 5-6 regular, 7-8 buena, 9 -10 excelente.

\begin{tabular}{lcc}
\hline Tipo de muestra & $\begin{array}{c}\text { Calidad general del } \\
\text { corte histológico }\end{array}$ & $\begin{array}{c}\text { Técnica } \\
\text { empleada }\end{array}$ \\
\hline Glándula mamaria & $9,5 \pm 1,25$ & TC \\
Colon & $9,0 \pm 1$ & TC \\
Riñón & $8,9 \pm 1,2$ & TC \\
Glándula mamaria & $9,2 \pm 1,95$ & TA \\
Colon & $8,1 \pm 3$ & TA \\
Riñón & $9,5 \pm 0,75$ & TA \\
\hline$*$ p $\leq 0.5$ & &
\end{tabular}
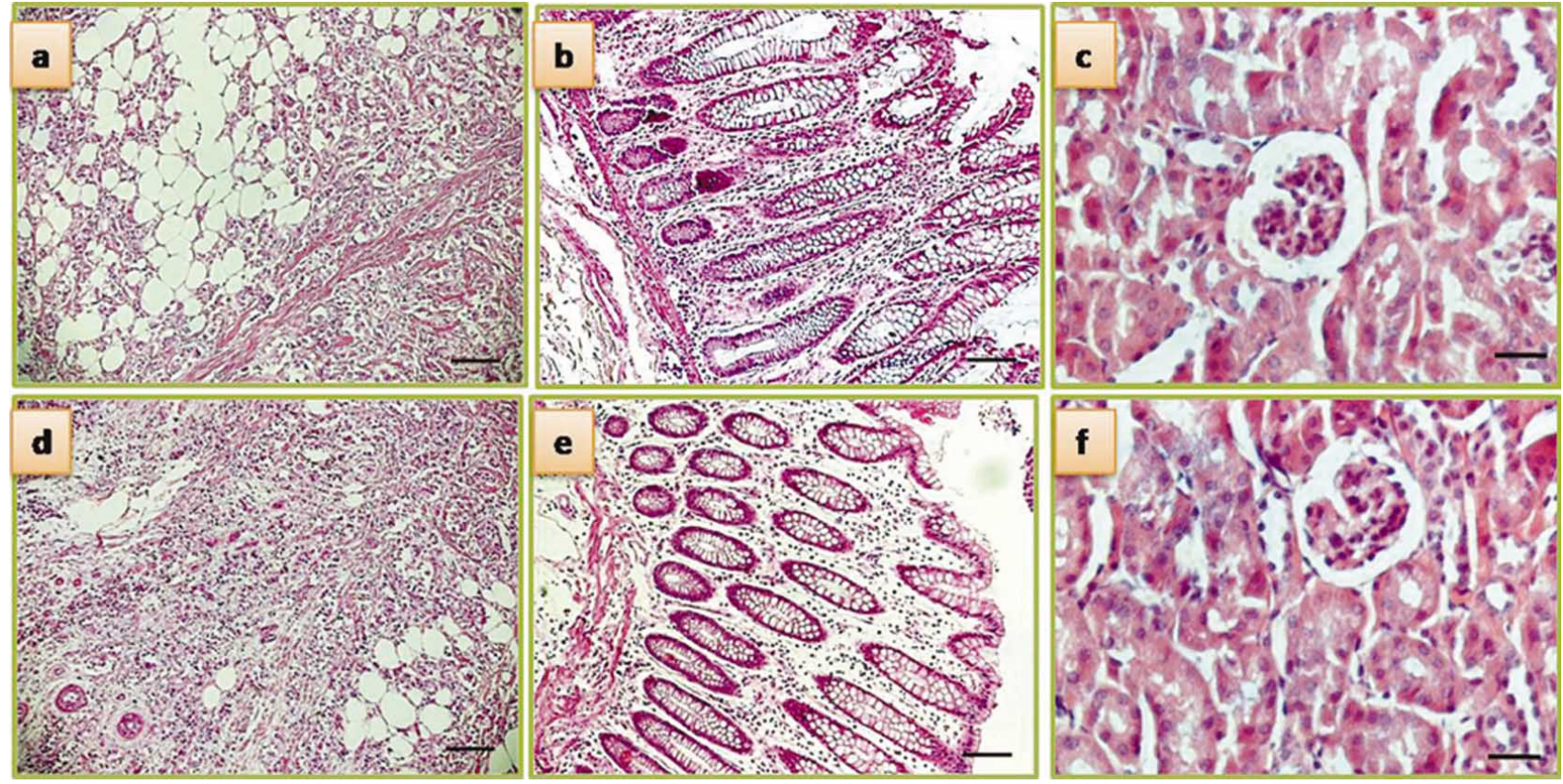

Fig. 1 a) Glándula mamaria TC; b) Colon TC; c) Riñon TC; d) Glándula mamaria TA; e) Colon TA; f) Riñon TA. Embebido en parafina $\mathrm{H} \&$ E. Barra $100 \mu \mathrm{m}$.

Calidad general del corte histológico. Los valores promedio obtenidos para el parámetro 3 estuvieron dentro del rango de $8,1 \pm 3-9,5 \pm 0,75$ para TA y de $8,9 \pm 1,2-9,5 \pm 1,25$ para TC. No se observó diferencia estadística significativa (Tabla III). 
MARTíNEZ, R. P.; PIÑA, O. A. K.; SOTO, D. A. \& GARCÍA, G. R. Comparación histológica e inmunohistoquimica de muestras de tejido procesadas por la técnica convencional o por el método simplificado de acetonas. Int. J. Morphol., 29(2):575-580, 2011.

Tinción con tricrómico de Masson. Para los parámetros 1,2 y 4 los valores promedio obtenidos estuvieron dentro del rango de 7,5 $\pm 0,7-8,1 \pm 1,2$ para TA y de 7,1 $\pm 1,3-8,2 \pm 0,9$ para la TC No se observó diferencia estadística significativa (Tabla IV).

Técnicas de inmunohistoquímica. Se observó que la sensibilidad y especificidad de los anticuerpos utilizados fue- ron similares en las muestras de tejido procesadas por ambas técnicas.

Cabe destacar que al observar las muestras teñidas con H y E (Fig. 1), Tricrómico de Masson (Fig. 2), e inmunohistoquímica (Fig. 3), no fue posible para los evaluadores el diferenciar cuál de ellas correspondía a cada técnica.
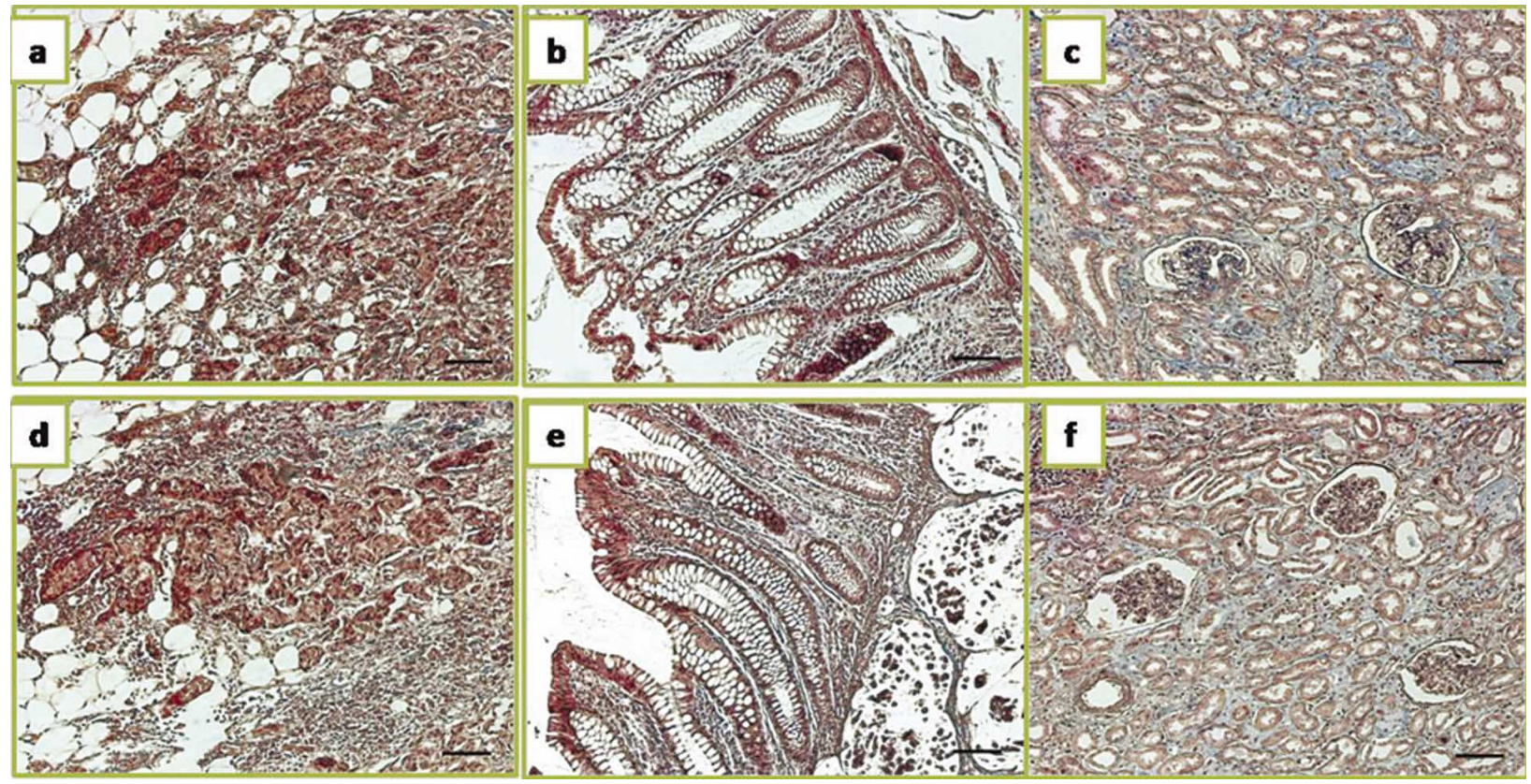

Fig. 2. a) Glándula mamaria TC, b) Colon TC, c) Riñón TC, d) Glándula mamaria TA, e) Colon TA y f) Riñón TA. Embebido en parafina, Tricrómico de Masson. Barra $100 \mu \mathrm{m}$.

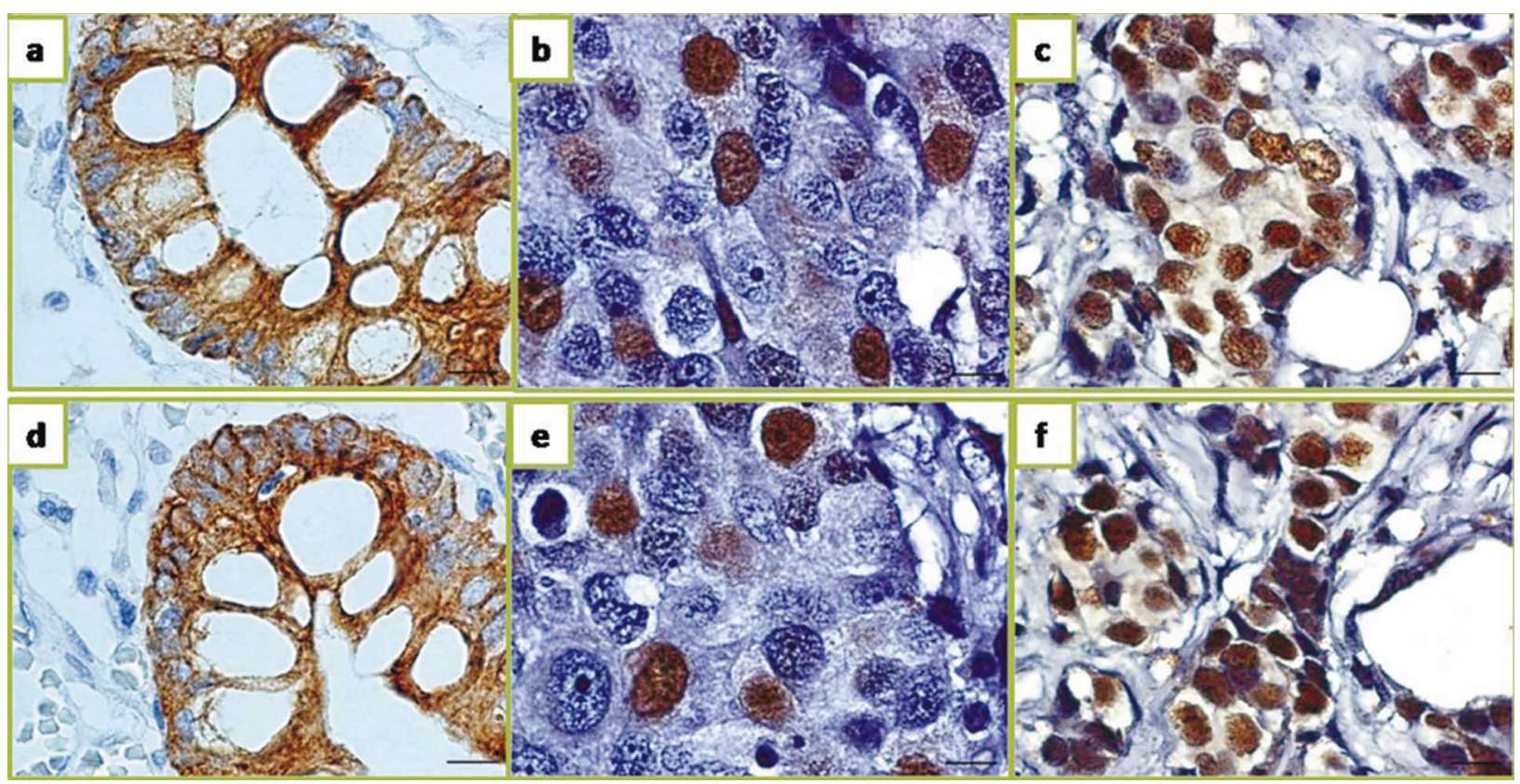

Fig. 3 a) CKAE1/AE. TC; b) Receptores de progesterona TC; c) Receptores de estrogenos TC; d) CKAE1/AE. TA; e) Receptores de progesterona TA; f) Receptores de estrogenos TA. Embebido en parafina. Muestra de inmunohistoquimica. Barra $100 \mu \mathrm{m}$. 
MARTíNEZ, R. P.; PIÑA, O. A. K.; SOTO, D. A. \& GARCÍA, G. R. Comparación histológica e inmunohistoquimica de muestras de tejido procesadas por la técnica convencional o por el método simplificado de acetonas. Int. J. Morphol., 29(2):575-580, 2011.

Tabla IV. Valores obtenidos en la evaluación histológica para las muestras teñidas con tricromico de Masson. 1y 2 corresponden a muestras de muy mala calidad, 3-4 mala calidad, 5-6 regular, 7-8 buena, 9 -10 excelente.

\begin{tabular}{lcccc}
\hline Tipo de muestra & $\begin{array}{c}\text { Promedio de tinción } \\
\text { nuclear }\end{array}$ & $\begin{array}{c}\text { Promedio de tinción } \\
\text { del citoplasma }\end{array}$ & $\begin{array}{c}\text { Promedio de tinción de } \\
\text { colágeno }\end{array}$ & Técnica empleada \\
\hline Glándula mamaria & $7.5 \pm 1.2$ & $7.9 \pm 1$ & $8.2 \pm 0.9$ & TC \\
Colon & $7.1 \pm 1.3$ & $7.8 \pm 1.2$ & $8.0 \pm 0.8$ & TC \\
Riñón & $7.4 \pm 1.3$ & $7.8 \pm 0.8$ & $7.9 \pm 1.1$ & TC \\
Glándula mamaria & $7.7 \pm 1.1$ & $7.5 \pm 0.7$ & $7.9 \pm 1.2$ & TA \\
Colon & $7.5 \pm 1.2$ & $7.8 \pm 0.8$ & $7.6 \pm 0.9$ & TA \\
Riñón & $7.6 \pm 1.3$ & $7.7 \pm 1.2$ & $8.1 \pm 1.2$ & TA \\
\hline
\end{tabular}

$* \mathrm{p} \leq 0.5$

\section{DISCUSIÓN}

El estudio de la anatomía patológica ha sufrido grandes avances importantes en las últimas décadas en búsqueda de diagnósticos más precisos y completos. Sin embargo, en el área de procesamiento de tejidos los avances han sido escasos, por lo que se continúa la búsqueda de métodos alternativos a la TC que nos permitan el obtener muestras procesadas en un menor tiempo, menor costo, que no represente riesgo al tejido ni al personal del técnico y sumado a lo anterior y como un parámetro se busca que el procesamiento importante no modifique la calidad de tejido ni sus propiedades tintoriales.

El tiempo para el procesamiento de tejidos por la TC tiene una duración aproximada de 12 horas (Prophet; Montuenga et al.). En nuestro estudio la aplicación de la TA en muestras de tejido redujo de manera considerable el tiempo de procesamiento hasta de aproximadamente 3:20 horas, esto se debe a que la acetona es un agente deshidratante mas potente que el alcohol lo que permite una disminución importante del tiempo del proceso. Cabe señalar que existen otros métodos de procesamiento mas rápidos que la TA como lo es la técnica de microondas (Hafajee \& Leong, 2004; Leong \& Price, 2004). Sin embargo a pesar del corto tiempo de procesamiento en éste método existen limitaciones como poder procesar muestras no mayores de $2 \mathrm{~mm}$, una gran cantidad de reactivos necesarios para su buen funcionamiento, riesgo de pérdida de muestra, o accidentes por manejo del personal inexperto (Estay et al., 2008).

En las muestras analizadas en nuestro estudio y procesadas por la TA se observaron valores promedio para la tinción de $\mathrm{H}$ y E entre 7,2 $\pm 0,5-8,1 \pm 0,9$ para la calidad de la tinción nuclear, 7,2 $\pm 0,5-7,5 \pm 1$ para la calidad de la tinción citoplásmica y $8,1 \pm 3-9,5 \pm 0,5$ para la calidad general del corte. En las muestras teñidas con tricrómico de Masson se obtuvieron valores promedio entre $7,5 \pm 1,2-7,7 \pm 1,1$ para la calidad de la tinción nuclear, 7,5 $\pm 0,7-7,8 \pm 0,8$ para la calidad de la tinción citoplásmica y 7,6 $60,9-8,1 \pm 1,2$ para la calidad de la tinción de la colágena, éstos valores fueron similares a los resultados observados para las muestras procesadas por la TC.

Otro aspecto importante fue de que en el estudio ciego, las muestras recibieron valores promedio similares con desviaciones estándar traslapadas, lo que nos permitió determinar que no existen diferencias estadísticas en la evaluación histológica e inmunohistoquímica entre las muestras procesadas. En base a nuestros resultados se sugiere el empleo de la TA en el laboratorio de histología e histopatología, ya que se observó una importante reducción en el tiempo de procesamiento, así como una disminución considerable en el costo de los reactivos utilizados. La TA no afectó la calidad del tejido ni modificó sus propiedades tintoriales que son importantes para el diagnóstico veraz y oportuno.

Actualmente en nuestro laboratorio se están realizando estudios que evalúen los parámetros descritos en muestras de otros órganos y/o distintos tipos de neoplasias.

\section{AGRADECIMIENTOS}

Agradecemos atentamente al Dr. Edmundo Castelan, al Dr. Eduardo Gonzalez y al personal tecnico de la clinica 25 del IMSS por su valioso apoyo en la elaboracion de este proyecto, asi como al M.C. Viktor Romero Diaz por facilitarnos la bibliografia correspondiente a la tecnica simplificada de acetonas. 
MARTÍNEZ, R. P.; PIÑA, O. A. K.; SOTO, D. A. \& GARCÍA, G. R. Histological and immunohistochemical comparison of tissue samples processed by the conventional technique or the acetone simplified method. Int. J. Morphol., 29(2):575-580, 2011.

SUMMARY: The conventional technique (CT) using alcohol as a drying agent, is a useful method of histology and pathology in the laboratory. Recently, a new simplified method with acetone (TA) was designed in an attempt to reduce the processing time of the tissues (12 to 4 hours), the cost of reagents, and as an important factor to have an accurate and prompt diagnosis . This study compared the histological and immunohistochemical parameters in breast cancer, colon and kidney specimens treated with both methods. The sections were stained with $\mathrm{H} \& \mathrm{E}$ or Masson trichrome. Immunohistochemistry study with antibodies specific for the identification of cytokeratin AE1/AE3, the estrogen receptor and progesterone receptor was also carried out. Blind study was conducted by three specialists in morphology, who evaluated the nuclear staining, staining of the cytoplasm and friability or changes in tissue structure. The specificity and sensitivity of antibody binding were also evaluated. The values obtained for each parameter were statistically analyzed with Student $\mathrm{t}$ test. Our results show that the methods of CT and TA did not alter histological features as the pattern of staining, and tissue changes were detected. Immunohistochemical positivity was similar for both methods. There was no statistical difference between TC and TA. Our results suggest that implementation of the TA did not alter the histological and immunohistochemical properties and could be a useful method for morphological analysis.

KEY WORDS: Alcohol; Acetone; Histological processing; Immunohistochemistry.

\section{REFERENCIAS BIBLIOGRÁFICAS}

Bancroft, J. D. \& Gamble, M. Theory and Practice of Histological Techniques. $5^{\text {th }}$ edn. London, Churchill Livingstone, 1997.

Estay, F. A.; Parra, L. R. \& Benítez, C. H. Procesamientos histologicos convencional y en microondas: Comparación histológica, histoquímica e inmunohistoquímica. Int. J. Morphol., 26(2):317-24, 2008.

Hafajee, Z. A. \& Leong, A. S. Ultra-rapid microwave simulated tissue processing with a modified protocol incorporating microwave fixation. Pathology, 36(4): 325-9, 2004.

Hidalgo, A.; Piña, P.; Guerrero, G.; Lazos, M. \& Salcedo, M. A simple method for the construction of small format tissue arrays. J. Clin. Pathol., 56(2):144-6, 2003.

Leong, A. \& Price, D. Incorporation on microwave tissue processing into a routine pathology laboratory: impact on turnaround times and laboratory work patterns. Pathology, 36(4):321-4, 2004.

Montuenga, B. L.; Esteban, R. F. J. \& Calvo, G. A. Técnicas en histología y biología celular. Barcelona, Elsevier Masson, 2009.

Prophet, E. B. Métodos Histotecnológicos. Washington D. C., Instituto de Patología de las Fuerzas Armadas de USA, 1995.
Romero D. V. Método Histotecnológico de procesamiento simplificado para tejido nervioso. Rev. Patol., 31(3):67, 1993

Dirección para correspondencia:

Dr. Rubén García Garza

Depto. de Histología

Facultad de Medicina

Universidad Autónoma de Nuevo León

Monterrey

Nuevo León

MEXICO

Email: rubergarcia85@hotmail.com

Recibido : 02-12-2010

Aceptado: 12-01-2011 